\title{
COGNIÇÃO E EMOÇÃO NA DINÂMICA DA DOBRA AFETIVA ${ }^{1}$
}

Jerusa Machado Rocha*

Virgínia Kastrup

RESUMO. Tradicionalmente, a psicologia tem considerado emoção e cognição como dois domínios separados, seguindo a tradição ocidental, que pensa a cognição como abstrata e desencarnada e a emoção como um fator predominantemente extracognitivo com base evolutiva. Este trabalho tem como objetivo repensar essa suposta separação e contribuir para o entendimento da produção conjunta da emoção e da cognição. Utilizamos como fundamentação teórica as ideias de Francisco Varela e Natalie Depraz sobre a dinâmica da dobra afetiva. De acordo com tal perspectiva, o eixo afetivo e pré-reflexivo se dobra ao constituir-se um segundo eixo, o qual se desdobra nas emoções e nos conteúdos cognitivos propriamente ditos. A emoção e o conteúdo cognitivo que a acompanha são atravessados por forças afetivas e o plano afetivo que atravessa o plano cognitivo-emotivo conecta cognição e emoção num coengendramento imanente.

Palavras-chave: Afeto; emoção; cognição.

\section{COGNITION AND EMOTION IN THE DYNAMICS OF THE AFFECTIVE FOLDING}

\begin{abstract}
Psychology has traditionally taken emotion and cognition into consideration as two separate domains, giving continuity to the Western tradition, which thinks cognition as abstract and unfleshed; and emotion as a predominantly extracognitive factor with an evolutive basis. This paper aims at rethinking this supposed separation and contributes to the understanding of the production of emotion together with cognition. As our theoretical basis we picked Francisco Varela and Natalie Depraz' ideas about the dynamics of the affective folding. According to such perspective, the affective and prereflexive axis bends while constituting a second axis that unfolds itself into emotions and cognitive contents. Emotion and cognitive contents are intersected by affective forces. The affective plan, which crosses the cognitive-emotive one, connects cognition and emotion in an immanent co-engenderment.
\end{abstract}

Key words: Affection; emotion; cognition.

\section{COGNICIÓN Y EMOCIÓN EN LA DINÁMICA DE LA DOBLA AFECTIVA}

RESUMEN. Tradicionalmente la psicología considera emoción y cognición como dos domínios separados, siguiendo la tradición occidental que piensa la cognición como abstracta y desencarnada y la emoción como um factor predominantemente extra-cognitivo con una base evolutiva. Ese trabajo tiene como objetivo repensar supuesta separación y contribuir para el entendimiento de la produción conjunta de la emoción y de la cognición. Utilizamos como fundamentación teórica las ideas de Francisco Varela y Natalie Depraz sobre la dinámica de la dobla afectiva. De acuerdo con tal perspectiva, el eje afectivo y pre-reflexivo se dobla al constituirse un segundo eje, que se desdobla en las emociones y en los contenidos cognitivos propiamente dichos. La emoción y el contenido cognitivo que la acompaña son atravesadas por fuerzas afectivas. El plan afectivo que atraviesa el plan cognitivo y emotivo conecta la cognición y la emoción en un engendramiento conjunto inmanente.

Palabras-clave: Afecto; emoción; cognición.

As flutuações emocionais que acompanham pensamentos e percepções do cotidiano têm sido consideradas por uma grande parte da psicologia cognitiva como um colorido ou um suplemento que se acrescenta aos processos de conhecimento. A psicologia tem privilegiado uma separação entre os domínios cognitivo e emotivo, e o principal motivo dessa separação é a forma como a emoção e a

\footnotetext{
Apoio: CNPq.

* Doutora, trabalha no Educar em Revista.

\# Doutora, Professora da Universidade Federal do Rio de Janeiro.
} 
cognição têm sido concebidas. $\mathrm{O}$ objetivo deste trabalho é repensar essa suposta separação e contribuir para o entendimento da produção conjunta da emoção e da cognição.

A emoção foi entendida, a partir das análises de Charles Darwin, como um fenômeno predominantemente somático, seguindo um modelo adaptativo e evolutivo. Darwin, que em 1872 trouxe uma das primeiras contribuições de destaque no âmbito científico, procura mostrar o que existe de característico nas manifestações expressivas de cada uma das espécies estudadas. Seu objetivo era determinar as mudanças que compõem a expressão de determinado estado emocional. A expressão é considerada como uma forma adaptada de resposta que teria sido útil na luta pela sobrevivência das espécies ao longo da evolução. No homem sua ocorrência evolutiva é vinculada ao domínio animal. A emoção humana é vista, muitas vezes, como um sinal de descontrole, em que é ativada uma dimensão primitiva, instintiva e irracional. Esta dimensão instintiva pode inclusive levar o homem a cometer atos de violência. Tal modo de pensar teve efeitos sobre a psicologia em seu entendimento da emoção como um impulso que deve ser controlado pela inteligência e sobre sua indicação de que as pessoas devem aprender a gerenciar e a disciplinar as emoções, bem como as situações que as ocasionam.

$\mathrm{Na}$ psicologia social as pesquisas de Schachter e Singer, em 1962, vinculam o problema da emoção ao da cognição. Os autores procuram mostrar que são necessários dois fatores para que ocorra um sentimento emocional. Ao lado dos fatores fisiológicos encontram-se os fatores cognitivos. A emoção passa a ser considerada como avaliação cognitiva de um fato social. A emoção torna-se cognição, no sentido em que consiste num julgamento que fazemos sobre o mundo. Implica uma avaliação, pelo sujeito, da significação do acontecimento vivido. A emoção julga o mundo como agradável ou desagradável, como bom ou mau, segundo um sistema de valores. Essa avaliação depende de fatores presentes na situação, mas também de fatores ligados à cultura e ao sujeito. Amar, odiar e ter medo são julgamentos emocionais individuais da situação social. A cólera, por exemplo, significa que a situação foi considerada como injusta, ameaçadora ou intolerável. O corpo não é mais o lugar privilegiado de leitura das emoções, pois estas são relacionadas ao contexto social.

Se na vertente somática a emoção foi considerada separada da cognição, na vertente social o ser comovido aparece como inteligente. A emoção não nos tira do domínio cognitivo, pois ela própria deriva de uma avaliação cognitiva. Não obstante, seguindo as análises de V. Despret (2006), fica evidenciado que alguma coisa é comum às duas vertentes. Seja a emoção um fato biológico ou social, ela é considerada, em ambos os casos, como uma resposta, de fundo adaptativo, a uma ação do exterior sobre o interior, numa causalidade única e unidirecional. A emoção é considerada passiva, sujeita às ações dos estímulos do meio. As duas vertentes a definem como interna ou mesmo íntima, sofrendo constrições do meio ambiente físico ou social. O sujeito deve sempre reagir a um conjunto de situações que lhe são propostas. Schachter e Singer (1962), por exemplo, encarnam tal perspectiva quando constroem diversos experimentos com situações que induzem o sujeito a sentir cólera ou euforia.

Ambas as vertentes aqui apresentadas, a que destaca o aspecto somático e a que privilegia o social, não colocam diretamente o problema da maneira como cognição e emoção são produzidas, elas partem do pressuposto de que são meros efeitos resultantes do meio ambiente físico e social. Embora os autores não tenham feito uma discussão teórica clara acerca do conceito de cognição, percebe-se que este é entendido como sinônimo de julgamento, avaliação e controle racionais de fatos sociais. $\mathrm{O}$ ser comovido torna-se senhor de si e de suas ações em função de sua cognição racional. A emoção pode e deve render-se à razão.

\section{ULTRAPASSANDO AS DICOTOMIAS}

A concepção da dinâmica da dobra de Francisco Varela e Natalie Depraz (2000) abre caminho para pensar o coengendramento entre emoção e cognição. A emoção não se rende à razão, tampouco o contrário. Emoção e cognição partilham o mesmo plano, de base afetiva, ou seja, são imanentes. Por outro lado, a noção de afeto em Gilles Deleuze (1992) permite uma melhor compreensão do que seria o plano afetivo. Para Deleuze, os afetos não são sentimentos pessoais, são forças que nos atravessam: "O sangue lateja sob a pele deste rosto de mulher, e o vento agita um ramo, um grupo de homens se apressa em partir" (Deleuze, 1992, p. 213). Os afetos não são de ordem interior, pois existem para além dos sujeitos que os vivenciam. Enfim, o afeto ultrapassa a separação entre sujeito e objeto. Em Varela e Depraz o afeto também está aquém dessa separação, na medida em que é concebido como força.

Num artigo que se propõe a distinguir termos próximos e correlatos como emoção e afeto, Depraz 
(1999) toma como base suas raízes etimológicas. A palavra latina affectio originou os vocábulos afeto, afecção, afetividade. Refere-se ao plano da facticidade, ou seja, o que me chega, o que se impõe a mim, aquilo que me faz, me constitui. $\mathrm{O}$ vocábulo $e x-$ movere origina os termos emoção, mover, colocar-se para fora de si. Enquanto o afeto está relacionado a um plano de constituição, a emoção (e-moção) está estreitamente relacionada com o campo do movimento (motus), sendo definida por ela como um "movimento im-pulsionado por outra coisa que eu mesmo e que me transporta para fora de mim, sem que esse movimento contenha, entretanto, implicado nele, qualquer direção ou finalidade" (Depraz, 1999, p. 122) ${ }^{2}$. Pode-se dizer, a partir daí, que aquilo que nos afeta produz algum tipo de movimento ou emoção e que essa emoção não se separa do afeto que a produziu.

Varela parte da biologia para pensar a cognição e por isto estabelece de imediato um domínio cognitivo que está aquém do humano. Na medida em que vivemos e agimos, conhecemos o mundo. Assim, a função cognitiva é viva e colocada num plano que não privilegia a mediação representativa e intelectual. Juntamente com Maturana formula a noção de autopoiese, segundo a qual o vivo é capaz de se autoconstituir, de criar a si e ao mundo num mesmo ato de coengendramento ou imanência. Com o conceito de enação Varela (2003) torna mais clara a ideia de que sujeito e mundo se constroem mutuamente. Não é o mundo que constitui o sujeito, tampouco o sujeito que constitui o mundo. Para além da dicotomia dentro/fora, o que é afirmado aqui é uma constituição conjunta. O mundo é en-agido, ou seja, ele emerge a partir das ações que estabelecemos no cotidiano, no qual nós também emergimos. $\mathrm{O}$ agir não parte de um eu, de um sujeito interiorizado, tampouco o mundo é uma projeção subjetiva.

\section{A DINÂMICA DA DOBRA}

A imanência entre os domínios afetivo, emotivo e cognitivo será explicada por Depraz e Varela seguindo a hipótese do que denominam dinâmica da dobra. A dobra desenvolve-se como uma transição, um movimento do plano pré-reflexivo ao plano reflexivo, do nível pré-egoico para o nível egoico e da atitude pré-atenta para a atitude atenta. Possui um duplo eixo: 1) um pré-reflexivo e autoafetivo, que se dobra e conduz a um segundo eixo; e 2) um segundo eixo, que

2 A tradução do texto é nossa, assim como a de todos os outros textos em idioma estrangeiro citados. se exprime como um leque de emoções e conteúdos cognitivos. $\mathrm{O}$ eixo da autoafetividade se baseia numa relação afetiva de si para consigo, que conduz ao segundo eixo ao se expressar numa gama de emoções e disposições básicas, tais como movimentos da face, postura, arrepios, etc. Nesse eixo primordial autoafetivo se encontra também o pré-reflexivo, que possibilita a emergência da própria reflexão ao se dobrar, conduzindo ao segundo eixo, o das emoções e conteúdos cognitivos. O lado mais próximo da dobra é aquele que nos constitui, o campo intensivo ou préreflexivo; o mais distante é aquele que se dirige aos objetos, o conteúdo intencional.

É importante compreender o sentido do vocábulo "auto" (self), de autoafecção (self-affection), utilizado por Varela e Depraz. "Auto" significa relação de si para consigo e se refere a um tipo de constituição de subjetividade ou de identidade. No entanto, identidade aqui não se refere a uma personalidade estática. $\mathrm{O}$ termo identidade é utilizado tomando como base a distinção de P. Ricoeur (1990, p.13), quando afirma que este termo possui uma equivocidade, pelo fato de poder se desdobrar em pelo menos duas significações: por um lado, idem, e por outro, ipse. A identidade no sentido de ipse não implica que se afirme um pretenso núcleo não cambiante da personalidade; já a identidade no sentido de idem (ou do mesmo) se opõe à identidade-ipse. Alteridade e ipseidade não se opõem. Muito ao contrário, o importante a observar é que a alteridade é constitutiva da própria ipseidade: “(...) a ipseidade do si mesmo implica a alteridade num grau tão íntimo que um não se deixa passar sem o outro (...)". (Ricoeur, 1990, p. 14)

$\mathrm{O}$ afeto é o elemento que, ao se repetir se diferenciando, no incessante desdobrar temporal, constitui uma categoria pré-pessoal e pré-egoica. Sendo assim, a subjetividade, constituindo-se nesse nível pré-pessoal, não seria nem substancialidade - na medida em que a ipseidade se constitui no constante diferenciar-se de si mesmo (ou alteridade) -, tampouco seria pura relação de exterioridade, pois é atravessada pelo tempo e por ele constituída de forma inseparável e autoafetiva. O afeto é, nesta medida, inseparável da temporalidade que nos constitui. $\mathrm{O}$ desdobrar temporal da autoafecção é atravessado pela alteridade, uma vez que a autoafecção é sempre um afeto incluindo outro, mesmo que esse outro seja o próprio si (si mesmo como outro). Na autoafecção somos ao mesmo tempo o afetante e o afetado. Em outras palavras, sou afetado por algo que me constitui. A autoafecção atravessada pela alteridade é um Si vazio de si, ou em diferenciação constante de si mesmo, já que atravessado pelo desdobrar do tempo. 
Dessa forma, o auto de autoafecção não tem o sentido de uma identidade não cambiante. Pelo contrário, sendo atravessado pela alteridade, o si mesmo está em constante mutação.

Segundo Varela e Depraz (2000), a manifestação mais imediata dessa alteridade é a valência afetiva e as disposições básicas que daí decorrem. A valência é a constituição primordial da autoafecção, sua primeira expressão, e surge como uma polaridade dinâmica. Devido a sua grande importância, a valência, que é potência de variação, é considerada aqui o germe ou semente primordial, ou seja, o invariante constitucional: "Iremos designar sob o termo valência a constituição primordial da autoafecção como uma polaridade dinâmica, manifestando-se na forma de uma tensão que toma várias formas: gostar/não gostar; atração/rejeição; prazer/desprazer" (Varela \& Depraz, 2000, p. 53). É importante observar que o que existe como invariante é a própria potência de variação. Esses pares de opostos são na verdade continuums limitados por extremos, que são neles mesmos, multiplicidades.

A polaridade dinâmica constitui o germe da emoção, conforme veremos mais adiante. Possui natureza transitória e inerentemente instável, uma simples flutuação a partir de um domínio préreflexivo, sendo apenas uma tendência, um movimento que se manifesta como o esboço de um próximo passo. A emergência da valência leva-nos até o limiar da dobra. Estamos ainda no estágio de uma experiência enevoada, descentrada de si, mas marcada por uma polaridade própria da valência.

Varela e Depraz (2000) afirmaram que nossa experiência é constituída primordialmente por diferenciações, intensidades, constelações afetivas. $\mathrm{O}$ afeto "alterado" está no coração da temporalidade. É importante destacar que o afeto é entendido aqui como força afetiva, ou seja, como intensidade ou gradação, tal como abordado por Husserl, em 1966, no livro Analysen zur passiven Synthesis, e descrito como vitalidade originária: "se ela [a força afetiva] diminui até o ponto zero, a vida cessa juntamente com sua própria vitalidade (...)" (citado por Varela \& Depraz, 2000).

A valência ou força afetiva manifesta-se como uma transformação dinâmica que envolve o corpo inteiro de forma complexa. Surge como uma tendência e se desdobra como relevo, ao produzir contornos. Isto ocorre, no mínimo, em dois eixos principais. Em primeiro lugar, o próprio movimento do corpo já manifesta um sinal de valor, que se situa entre uma polaridade, - o movimento de fuga ou o de ir ao encontro de algo. Em segundo lugar, esse movimento manifesta-se como uma disposição básica composta de uma variedade de dimensões afetivas, cuja parte visível manifesta-se de diversas formas - posição, postura, movimentos faciais - e como um complexo de componentes autônomos, como, por exemplo, o batimento cardíaco, a respiração, sensações de arrepio na pele, etc.

Retomando o que foi dito, o nível afetivo primordial participa da dinâmica da dobra, que possui um duplo eixo. Por um lado, o nível autoafetivo se dobra conduzindo a predisposições básicas, como a postura corporal, e a uma gama específica de emoções. Por outro, essa mesma flutuação primordial pré-reflexiva desemboca na emergência dos conteúdos cognitivos e do nível reflexivo propriamente dito. Esses dois níveis interagem e se codeterminam. É importante perceber que, nessa dinâmica, os dois eixos se entrelaçam numa dimensão de cossurgimento, em que o nível pré-reflexivo se dobra em direção ao reflexivo, que, por sua vez, influencia e afeta o préreflexivo. A polaridade afetiva ou valência é o que constituirá a emoção, o lado ativo da constituição subjetiva temporal. Dessa forma, o afeto e a emoção se codeterminam formando um bloco e uma dinâmica. Os conteúdos cognitivos, por sua vez, também podem produzir quebras e tensões, que produzirão novos afetos e novos conteúdos.

Varela e Depraz seguem o pensamento de Max Scheler, para quem nossa experiência é, desde sempre, constituída por valores. Em outras palavras, não existe uma neutralidade primária da experiência. Não obstante, é necessário entender o que está sendo denominado de valor que Varela traz para sua formulação de valência afetiva. Valor não significa aqui um julgamento do mundo enquanto conteúdo cognitivo, mas um afeto, ou um sentir primordial, que aumenta ou diminui nossa potência, como se o mundo subitamente se tornasse luminoso ou sombrio. O que existe é uma experiência enevoada, descentrada de si, e o sujeito, com suas emoções e cognições, se constituirá a partir desse campo intensivo.

Para discutir o papel da valência Varela e Depraz propõem uma análise fenomenológica re-enagida (reenacted) para discutir o papel da valência. Como foi dito, na abordagem da enação, sujeito e mundo se constituem mutuamente. $\mathrm{O}$ agir sobre o mundo é sempre uma ação sobre si, uma autoconstituição. Dessa forma, os autores não se limitam a fazer uma análise fenomenológica puramente descritiva, mas analisam a fnomenologia no domínio empírico e experiencial. Tomam como base os trabalhos husserlianos de orientação genética, ou seja, do período em que Husserl ultrapassa uma 
fenomenologia estática do tempo (após 1920). O principal insight que recuperam de Husserl em Experience and Judgement, 1954, é a manifestação primária do afeto como produtor de contornos $\mathrm{e}$ orientações fundamentais do mundo: "Essa descoberta fundamental da análise genética coloca-nos perfeitamente no caminho da inseparabilidade entre o afeto e a cognição, entre os valores e a vida ela mesma" (Varela \& Depraz, 2000, p. 147). Sendo assim, é com a força afetiva que o mundo ganha forma e se manifesta como relevo (abhebung) que, ao se projetar, forma um contraste que nos desperta, como sob um golpe. A ideia de Husserl é que "sou afetado por algum dado sensorial, atraído por alguma tendência afetiva que me habilita a me orientar a mim mesmo receptivamente no espaço e no mundo. Em outras palavras, seja o que for que me afete, não posso ter uma experiência crua como protoimpressões ou impactos (Uraffektion)" (citado por Varela \& Depraz, 2000). Mesmo a primeira aparição já é perpassada por tendências afetivas, num mundo esboçado de maneira pré-egoica.

No campo da biologia, Jakob Von Uexkül (s/d) propõe a noção de mundo-próprio (Unwelt), a partir do ambiente afetivo de cada ser vivo. Toma como exemplo o caso do carrapato. Segundo sua descrição, é o afeto da luz que faz com que a fêmea já fecundada, mesmo sem olhos, suba com suas oito patas à parte superior de um arbusto que lhe agrade. Em seguida, é o afeto do cheiro de ácido butírico, exalado pelos mamíferos, que a faz perceber, mesmo sem nada ouvir, a presa sobre a qual ela irá se lançar. Por fim, vai procurar uma zona livre de pelos e saborear seu lauto festim de sangue quente (Uexküll, s/d, p. 29). Os afetos são, de imediato, um preenchimento ou um esvaziamento do mundo próprio do carrapato, um aumento ou uma diminuição. Podemos perceber, também, como no mundo dos cegos os afetos auditivos e táteis se desenvolvem e se aguçam, tornando-se uma fonte de referência importante para sua orientação no mundo. A percepção, portanto, está entrelaçada com o mundo afetivo, como uma forma de orientação, de ação pré-formada, e toda ação faz parte do mundo construído por cada um a partir dos impactos afetivos que nos despertam.

Embora Varela e Depraz utilizem o termo receptividade, uma consciência pré-reflexiva está em ação. Esta possui ao mesmo tempo uma dimensão ativa e passiva. De saída, o mundo já me toca, possui relevo, rugosidade, sendo segmentado de acordo com uma perspectiva afetiva. Surge daí a inseparabilidade entre o domínio cognitivo e o afetivo. Da mesma forma, o nível que antecede a atenção e a reflexão não pode se separar da atenção e da reflexão propriamente ditas, formando um duplo elo que vai do pré-atento ao atento, do pré-reflexivo ao reflexivo. O mesmo ocorre com o domínio autoafetivo, que se desdobra em direção a um "arco-íris" de emoções.

Não obstante, embora dizer de saída que o mundo me toca, possui rugosidades e relevos, possa dar a entender que a percepção é um ato natural de representação de um mundo preexistente, é preciso esclarecer que o nível afetocognitivo também pressupõe uma gênese, tal como o afetoemotivo. $\mathrm{O}$ mundo dos objetos não está previamente dado, mas precisa ser construído. Conquanto Varela e Depraz (2000) não explorem aqui a noção de cognição como criação, o próprio conceito de enação, retomado, já pressupõe que sujeito e mundo se constroem mutuamente. A percepção não é, destarte, apreensão de formas, mas invenção de formas. $\mathrm{O}$ mundo se polariza de tal maneira que a situação ganha um sentido. Perceber é, antes de tudo, solucionar uma tensão, um conflito, modificando a relação entre sujeito e mundo. Como afirmou Escóssia (2004)

A percepção precoce de animais por crianças deve ser apreendida como o efeito de uma tensão entre a criança e o animal, em uma situação polarizada por afetos de medo ou de encantamento, simpatia ou repulsa, que engajam corporalmente criança e animal no ato de percepção (Escóssia, 2004, p. 106).

A força afetiva ou a flutuação original manifesta-se como uma transformação rápida, dinâmica, de uma tendência à emergência de contornos e formas, envolvendo o corpo inteiro como um complexo que possui, no mínimo, dois eixos principais. 1) Há um movimento corporificado que se manifesta como possuído por uma força afetiva (affect-feeling force). $\mathrm{O}$ movimento é parte integral dessa dinâmica constitutiva e possui uma dupla polaridade: pode ser de valência negativa, como a reação imediata que ocorre ao taparmos os olhos com as mãos para nos afastarmos de um perigo, ou, de valência positiva, como o prazer advindo de escutarmos uma música que nos emociona até às lágrimas e que pode ser seguido de respiração expansiva e postura de fruição (reclinar das costas). Nesse nível básico, já se manifesta, então, um sinal de valor: afastar-se ou ir ao encontro de algo ou alguém. 2) Tal movimento é inseparável de sua manifestação visível: postura, posição, mudanças na face, na respiração, batimento cardíaco, sensações de 
arrepio, etc.; e apresenta componentes invisíveis com mudanças difusas: o tom da voz, a inflexão do olhar, um certo direcionamento no movimento, etc.

Cabe insistir que essa bipolaridade é, na verdade, uma multiplicidade, na medida em que o eixo entre atração e rejeição é dinâmico e está em contínua variação. Sendo assim, mais do que apresentar pares opostos, esse eixo é gerador de possíveis, constituindo uma alternativa mais topológica do que simbólica entre um sinal de mais e outro de menos. Mas como a valência ganha corpo? Como esta polaridade se manifesta corporalmente? Ela surge e se manifesta no limiar da dobra, para aonde a emergência da valência nos leva. De acordo com Varela e Depraz, a corporeidade da valência não é marcada pelo aparecimento completo de um centro egoico nem por um conteúdo intencional completamente formado. Embora se esteja ainda numa experiência enevoada e descentrada, essa polaridade própria da valência irá progressivamente ficar mais encarnada na manifestação de um interesse e numa prontidão para a ação (Varela \& Depraz, 2000, p. 158). Esses domínios de interesse são marcados por uma "topologia acidentada" do eu/outro, um ego vazio nascente, na origem de um "centro de gravidade" que se dirige à ação:

\begin{abstract}
Essa polaridade eu-outro expressa então a flutuação original na valência como uma articulação mais ampla a partir da fonte da autoafecção, num relacionamento mais amplamente constituído, com o mundo e com os outros. Esse domínio de interesse teve uma estrutura originariamente bem descrita pelo surgimento de uma relação imanente euoutro na formação de um nível pré-reflexivo (Varela \& Depraz, 2000, p. 159).
\end{abstract}

Cada domínio de interesse pode manifestar um amplo leque do repertório emocional, e a emoção é sempre já situada e corporificada. Esses domínios de interesse são disposições intersubjetivas: na inter-ação com os outros no dia-a-dia; nas relações globais e múltiplas com o outro; e num nível mais básico, que permanece indiferenciado e anônimo. Embora Varela e Depraz tomem de empréstimo o termo "interindividual" proveniente da fenomenologia husserliana, parecem sustentar uma concepção própria, na medida em que afirmam que, num nível mais básico, esses domínios de interesse permanecem indiferenciados e anônimos, não se fechando numa individualidade privada. Segundo Varela e Depraz, a análise husserliana permanece limitada, visto que não indica o papel preciso desempenhado pelo afeto na experiência empírica presente. Afastam-se de Husserl, bem como de outros teóricos da fenomenologia ${ }^{3}$, em dois aspectos importantes, ambos relativos ao aspecto eminentemente filosófico de suas investigações. Criticam a natureza abstrata dessas pesquisas e o distanciamento de relatos específicos referentes a emoções vividas, bem como total ausência de relação com trabalhos empíricos recentes (Varela \& Depraz, 2000, p. 148). Dessa forma, os autores se preocupam em pensar a afetoemotividade a partir de análises empíricas, regressivas e progressivas, conforme veremos a seguir.

\section{A AFETOEMOTIVIDADE NAS PESQUISAS EMPÍRICAS}

Uma análise temporalmente regressiva explica como a valência ocorre no domínio empírico. A flutuação original da valência se desenvolve de forma dinâmica e integrada como numa constelação, uma vez que seus momentos não são sucessivos e lineares, mas surgem de forma conjunta. Uma tendência é seguida por uma mudança na atenção, que se destaca e ganha relevo. Isto significa que ela se corporifica e ganha forma, e que, manifestando-se numa microtemporalidade, gera novas tendências, e assim sucessivamente. $\mathrm{O}$ momento presente surge dessa flutuação primordial. Podemos exemplificar a análise regressiva com a descrição, feita pelo próprio Varela, de uma experiência singular e passageira:

Hoje fui ao concerto às 11:00 h. Como cenário, uma certa opressão em minhas pálpebras, e um pouco de tristeza. Me sento inclinado em direção ao segundo balcão. Os músicos (sublime conjunto italiano), chegam, afinam e se acalmam. Um curto silêncio, e então começam com a sonata Musical Offering, que adoro. Instantaneamente, com as primeiras cinco ou seis notas do tema principal, eis que surge uma mudança no humor e na tonalidade afetiva (feeling tone): subitamente meu peito respira profundamente, minha pele fica arrepiada e é como se o corpo fosse levado para o lugar. Quase ao mesmo tempo há uma onda de beleza, de pungência, a qual trouxe subitamente lágrimas aos meus olhos, uma respiração intensificada. Sem premeditação

Os autores clássicos citados por eles são: M. Heiddeger, M. Merleau-Ponty, E. Levinas, M. Henry e Marion. A despeito do importante avanço realizado por esses autores, Varela considera importante ampliar a investigação fenomenológica para o domínio empírico. 
sinto meus olhos fecharem e me reclino para trás para relaxar meu corpo numa completa receptividade. Meu espaço mental parece se ampliar, e meu ego fica quase imperceptível. Quando vem a primeira variação do tema musical a tonalidade afetiva está completamente formada e a primeira onda de divagação começa. A primeira sendo a memória de uma outra ocasião quando a mesma música também me levou às lágrimas. A coisa toda durou uma mera fração de segundo (Varela \& Depraz, 2000, p. 150)

A dimensão de cossurgimento é marcada pela singularidade na dobra do momento presente. A música, cuja natureza compósita já se manifesta nas primeiras notas, ao se exprimir gera tendência, movimento e emoção num único bloco. Ao se deixar levar pela música, Varela estava voltado para si e ao mesmo tempo alinhado com o mundo musical circundante. A emoção e o conteúdo cognitivo surgem dessa experiência.

A experiência de desviar o olhar é outra experiência para explicar a flutuação da valência, tal como aparece numa análise de Merleau-Ponty em $O$ Visível e o Invisível (1964/2005). Quando tapamos os olhos para não ver alguma coisa que nos fere ou enoja não estamos simplesmente acreditando que só existe um mundo interior, privado, e que, ao desviarmos o olhar, o que nos afeta deixaria de existir. Ao invés disso, acreditamos que nossa visão vai às coisas nelas mesmas. A experiência de tapar os olhos mostra que a presença perceptiva do mundo, para aquém de qualquer julgamento, afirmação ou negação, é a experiência do habitar o mundo com nosso corpo (Varela \& Depraz, 2000, p. 150). Alguns exemplos são desviar o olhar ao ver um acidentado na estrada, ou ao ver alguém com uma gilete cortando a própria carne. A experiência que nos provoca uma repulsa imediata é um exemplo de uma valência negativa que ocorre antes mesmo que se faça um julgamento sobre a situação.

Num segundo passo metodológico, Varela e Depraz vão propor uma análise progressiva da valência. Para isto, analisam o papel da valência, também no nível empírico, a partir das origens do ser vivo. A proposta objetiva, antes de tudo, é mostrar como o mundo animal, e mesmo o celular, já são marcados pela invenção de um modo de ser, numa busca ativa de nutrição, inseparável de um movimento afetivo. A constituição afetiva na história da vida é analisada a partir da perspectiva da enação, em que a vida e o meio ambiente encontram-se entrelaçados, numa constituição mútua (Varela, Thompson \& Rosch, 2003). O caráter enativo pode ser descrito através de dois eixos complementares. Por um lado, a vida animal é derivada de um acoplamento entre organismo e contexto, mediado pelas atividades sensório-motoras; por outro, o organismo é constituído pela emergência de configurações endógenas (modelos de auto-organização) de sua atividade interneural. $\mathrm{O}$ mundo de significações vai se configurar a partir dos movimentos afetivos que compõem a vida animal: "Assim, sentido e propósito são originários de um acoplamento sensório-motor modulado numa progressiva atividade endógena que o organismo configura num incessante fluxo em direção a um mundo de significações" (Varela et al., p. 156). O elo sensório-efetor está, portanto, no coração da vida animal, e os autores afirmam aqui que a característica mais básica de tal modo de constituição é a manifestação da autoafecção, que conduz à nutrição, sustentando e viabilizando essa possibilidade. Consideram que a própria constituição do sistema nervoso se faz a partir de um nível afetivo, em que tempo, espaço e afeto se unem num movimento sincronizado:

A manifestação mais elementar é uma tendência, uma inclinação, um deslocamento relativo para a topografia do organismo necessariamente atravessando um continuum que cobre as escolhas de uma ação ancorada na existência, mas inseparável de um mundo de significância. Nessa constituição básica da vida animal, espaço, tempo e afeto surgem juntos na topologia única que o movimento mais elementar pode ter dado a constituição do sistema nervoso: a valência, ir à (towards), e fugir de (away). Em outras palavras esse é um modo original, o germe dinâmico originário na fonte do afeto (Varela \& Depraz, 2000, p. 157).

Como inicialmente apontado, Depraz, adota o termo e-motion (seguindo os insights de Glen Mazis, 1999), para marcar a importância do movimento nessa dimensão de cossurgimento. Desta forma, a $e$-moção não se separa de um movimento que, ao se tornar corporal, manifesta-se numa microtemporalidade. A emergência de cada momento no desdobrar temporal surge de uma flutuação primordial. A força afetiva implica, portanto, uma tendência (pulsão ${ }^{4}$ ) e um movimento que se desenvolvem "no tempo e como tempo" (Varela \& Depraz, 2000, p. 152): "O afetoemoção surge de uma rede extremamente estendida que pode ser vista na natureza compósita do afeto. $\mathrm{O}$

4 Nesse artigo, o termo "pulsão" significa um movimento da valência afetiva, único, embora complexo. 
afeto une virtualmente cada tipo de qualidade que o organismo manifesta" (Varela \& Depraz, 2000, p. 163).

Afeto e emoção se codeterminam no movimento da valência afetiva. Ou seja, o afeto é a potência de variação, constituindo uma força que mobiliza e $e$ mociona. Dessa forma, a emoção está ligada a uma ação possível, realizando o movimento que tal força afetiva manifesta. $\mathrm{O}$ afeto é compreendido como inseparável de uma vitalidade e de uma atividade que lhe são consecutivas. Se, por um lado, o afeto é aquilo que nos constitui no fluxo temporal, como protensão, dirigido ao futuro, por outro, é aquilo que nos força a agir e que se desenvolve numa ação. Destarte, tal constituição não é uma simples passividade, mas uma mistura de passividade e atividade. ${ }^{5} \mathrm{O}$ afeto e a emoção são aqui mais do que simplesmente um tipo de experiência entre outras, mas solo original para a emergência da consciência na temporalidade (Varela \& Depraz, 2000, p. 164).

\section{A IMANÊNCIA AFETIVA NA COGNIÇÃO E NA EMOÇÃO CRIADORA}

Essa concepção pressupõe, antes de tudo, que a cognição surge de um plano de afeto. O si e o mundo não são previamente dados, mas construídos na constante mutação provocada pelo elemento afetivo, que está colado ao tempo. $\mathrm{O}$ afeto constitui o si e produz nele uma radical abertura, um inesperado, que o faz diferir incessantemente. Seguindo a perspectiva da enação, o afeto é pensado como uma disposição, e surge a partir de nosso envolvimento no mundo. Essa disposição surge a partir das forças afetivas que nos compõem, e que se expressam como expectativa do modo no qual o mundo irá mostrar-se, pré-condição para a emoção que também poderá vir a surgir. $\mathrm{O}$ ciumento, por exemplo, está sempre atento para os sinais de traição no rosto da amada. O afeto não apenas cria condições para a emoção, mas também permanece enquanto tonalidade virtual nas emoções específicas. Assim, quando vamos escrever um texto, dispomo-nos antecipadamente a um movimento, que dirige nossa atenção para o modo como vamos expressar determinado pensamento. Esta disposição afetiva está misturada com as emoções que carregamos, que podem ser de ansiedade ou de ressentimento por não encontrarmos a expressão apropriada. À medida que o texto começa a fluir,

5 Glen Mazis (1986) explica detalhadamente esse misto paradoxal em seu artigo Merleau-Ponty: l'habiter et les émotions. outras emoções e disposições surgem. Começamos a nos alegrar por encontrar as palavras que vão compor o texto, e nosso engajamento se torna mais fluido e promissor. Se nesse acoplamento, com as palavras e com o papel, subitamente somos desviados pelo telefone que toca, outras disposições e emoções irão surgir.

Henri Bergson, ao propor o conceito de emoção criadora (1932/1978), percebe a dificuldade com que se depara a psicologia ao considerar a emoção como um fator extracognitivo. Afirma que a questão que inspira interesse vem sempre investida de certa emoção, "sendo ao mesmo tempo curiosidade, desejo e gozo antecipado de resolver um problema determinado (...). Ela é que impele a inteligência para frente, apesar dos obstáculos" (Bergson, 1932/1978, p. 38). Ele distingue dois tipos de emoção, duas variedades de sentimento e duas manifestações da sensibilidade. A primeira é definida como um "revolver das profundezas", enquanto a segunda "uma agitação da superfície".

No primeiro caso o movimento é total, e "o todo é impulsionado para frente", indiviso; no segundo, o efeito se dispersa numa "oscilação das partes sem deslocamento do todo". Na agitação superficial da sensibilidade, a emoção é consequência de uma ideia ou imagem representada. O estado sensível resulta de um estado intelectual que lhe é exterior, pois se basta a si mesmo. Não obstante, no primeiro caso a emoção não é determinada pela representação, tampouco se separa das ideias que daí surgem. Essa emoção seria mais do que um efeito dos estados intelectuais, pois é prenhe de ideias e representações que podem daí derivar, não estando ainda totalmente formada. A emoção de que se ocupam os psicólogos, escreveu Bergson, é a segunda, que é infraintelectual, e "é nela que se pensa quando se contrasta a sensibilidade com a inteligência" (Bergson, 1932/1978, p. 37); entretanto, a primeira é supraintelectual, no sentido de que é ela que engendra ideias e as representações, sendo por isso anterior à segunda. Apenas a emoção de primeiro gênero é fértil em ideias.

Embora Bergson não distinga emoção de afeto, percebemos que em sua concepção de emoção supraintelectual já está incluso o componente afetivo. Ela é fértil em ideias por estar imersa no plano afetivo que a compõe. Ao contrário, a emoção infraintelectual funciona de forma passiva, apenas como reação aos estímulos do meio.

Por outro lado, a inteligência, isenta da emoção supraintelectual, ou desconectada de um plano afetivo, "labora a frio", numa combinação de ideias entre si, com palavras prontas entregues pela sociedade "em 
estado sólido", advindas da representação. Não há aí criação, apenas uma combinação de ideias e palavras pré-fabricadas. Bergson dá como exemplo o escritor: "Quem se empenhe na composição literária terá verificado a diferença entre a inteligência entregue a si mesma e aquela que consome com seu fogo a emoção original e única, nascida de uma coincidência entre o autor e seu assunto, isto é, de uma intuição" (Bergson, 1932/1978, p. 38). No primeiro caso o espírito trabalha a frio, combinando ecom palavras já definidas e demarcadas culturalmente pela sociedade; já no segundo caso, as ideias precisam ser experimentadas e vividas pelo autor. Ele é arrebatado por algo único, por uma força inesperada que o impele à criação e, só então, ele procura palavras que possam exprimir essa intuição, num esforço doloroso para que essa concepção venha à luz.

Essa emoção que procura meios para se expressar, que pode até não conseguir boas definições, ou exibirse mal conceitualmente, mas que foi tomada por algo de inesperado e singular, antecede a representação, e só depois busca palavras ou expressões capazes de traduzir o que ela continha virtualmente: "Ao lado da emoção que é o efeito da representação e que a ela se acrescenta, existe aquela que precede a representação, que a contém virtualmente e que até certo ponto lhe é causa" (Bergson, 1932/1978, p. 38). Quando vamos ao teatro, ou assistimos a um filme, ele poderá abalar nossos nervos, nos suscitar lágrimas, risos ou temores, mas todas essas emoções serão banais se colhidas entre as que sentimos normalmente na vida diária, e por isso serão vazias de representações, pois não conterão nenhuma fertilidade criadora.

Quando Varela define a cognição como viva, autopoiética ou enativa, produz ressonâncias com o que afirma Bergson sobre a emoção criadora. A cognição criadora é aquela capaz de mudar nossa tonalidade emocional, produzida a partir de uma instabilidade que nos desloca, que nos arrasta para outro lugar. Assim, a cognição é imanente à emoção, e ambas são criadoras. Dessa forma, a emoção, que é fecunda, retroage sobre o plano afetivo que a originou, produzindo novas cognições e emoções numa circularidade imanente. As emoções que, segundo Bergson, são geradoras de pensamento, através de uma manifestação profunda da sensibilidade, ou de um revolver das profundezas, estão conectadas na imanência do que denominamos de plano afetivo; mas a agitação superficial da sensibilidade produz um tipo de emoção que é mais efeito do que causa dos estados intelectuais. Nesse segundo caso, o pensamento labora a frio, e a emoção constitui apenas uma reação, pois está desconectada de seu elemento criador.

\section{CONSIDERAÇÕES FINAIS}

A partir dessas análises podemos conceber uma emoção que não é pura passividade, como afirma a psicologia tradicional, mas movimento de diferenciação, na medida em que se conecta com o campo de forças afetivas. Por outro lado, a cognição não se confunde com a racionalidade, ou com ideias abstratas, mas com uma imbricação eu/mundo atravessada por forças afetivas. Embora emoção e cognição sejam, de direito, unidas, podem se apresentar, de fato, separadamente. Tanto a emoção como mera agitação da sensibilidade, quanto a inteligência, como puro virtuosismo racional, estão desconectadas desse plano afetivo e criador. O afeto é o plano imanente de onde se desdobram emoções e cognições. Essas, por sua vez, refluem sobre o plano afetivo, numa circularidade imanente. Afeto e emoção se codeterminam no movimento da valência afetiva. $\mathrm{O}$ afeto é uma força que mobiliza e e-mociona. A emoção é o movimento que nos predispõe a agir. A cognição surge no acoplamento com o mundo, nas ações que executamos, por isso não se separa do plano dos afetos e das emoções.

\section{REFERÊNCIAS}

Bergson, H. (1978). As duas fontes da moral e da religião. (N. Caixeiro, Trad.). Rio de Janeiro: Zahar (Original publicado em 1932).

Deleuze, G. (1992). O que é a filosofia? (B. Prado Jr. e A. Muñoz, Trad.). Rio de Janeiro: Editora 34.

Depraz, N. (1999). Delimitation de l'émotion. Revue de phénoménologie. Émotion et affectivité, 7, 121-148. Paris: Éditions alter.

Despret, V. (2006). Ces émotions qui nous fabriquent. Ethnopsychologie des émotions. Paris: Les empêcheurs de penser en rond.

Escóssia, L. da (2004). O coletivo como plano de co-engendramento do indivíduo e da sociedade. Tese de Doutorado Não-Publicada, Programa de Pós-Graduação em Psicologia da Universidade Federal do Rio de Janeiro, Rio de Janeiro.

Mazis, G. (1999). Merleau-Ponty: L'habiter et les émotions. Revue de phénoménologie. Émotion et affectivité, 7, 285-305. Paris: Éditions Alter.

Merleau-Ponty, M. (2005). O Visível e o invisível. (J. A Gianotti e A M. de Oliveira, Trad.). São Paulo: Perspectiva (Original publicado em 1964).

Ricoeur, P. (1990). Soi-même comme um autre. Paris: Seuil.

Schachter S. e Singer J. (1962). Cognitive, social and phisiological determinants of emotional states. Psychological Review, 69(5): 379-399.

Uexküll, J. (s/d). Dos Animais e dos Homens. Digressões pelos seus próprios mundos. (A. Candeias e A. G. Pereira, Trad.). Coleção 
Vida e Cultura. Lisboa: Livros do Brasil (Original publicado em 1934).

Varela, F. (2003). O desencantamento do abstrato. Em P. P. Pélbart \& R. da Costa (Orgs.), Reencantamento do concreto (pp. 72-86). São Paulo: Hucitec.

Varela, F; Depraz, N. (2000). At the source of time: valence and the constitutional dynamics of affect. Recuperado em 10 de maio de 2002 em www.arobase.to/v4_n1_2/varela.pdfs
Varela, F., Thompson, E \& Rosch, E. (2003). A Mente Incorporada. Ciências Cognitivas e Experiência Humana. (M. R. S. Hofmeister, Trad.). Porto Alegre: Artmed.

Recebido em 28/11/2007

Aceito em 30/09/2008

Endereço para correspondência :

Jerusa Machado Rocha, Rua Casimiro de Abreu, 26/1302, Ingá, CEP 24210440- Rio de JaneiroRJ,Brasil.E-mail: jerusar@ig.com.br 